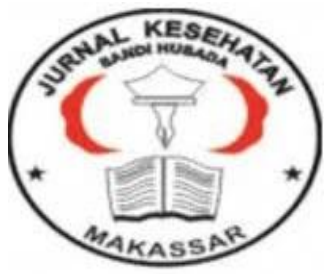

Jurnal Ilmiah Kesehatan Sandi Husada

hhttps://akper-sandikarsa.e-journal.id/JIKSH

Volume, Nomor 2, Desember 2020, pp761-766

p-ISSN: 2354-6093 dan e-ISSN: 2654-4563

DOI: $10.35816 /$ jiskh.v10i2.407

\title{
Aromaterapi Lavender sebagai Penurun Tingkat Kecemasan Persalinan
}

Lavender Aromatherapy for Reducing Anxiety Level of Labor

Annisa Ridha Salsabilla

Fakultas Kedokteran, Universitas Lampung

\section{Artikel info}

Artikel history:

Received; Juli 2020

Revised: Agustus 2020

Accepted; Agustus 2020

\begin{abstract}
Abstrak
Latar Belakang: Kecemasan adalah suatu kondisi kejiwaan yang penuh dengan kekhawatiran terhadap apa yang mungkin terjadi. Kecemasan akan meningkat pada saat ibu merasakan tanda-tanda kesakitan melahirkan bayinya. Upaya untuk menurunkan tingkat kecemasan dapat menggunakan aromaterapi lavender, dengan melakukan pemijatan maupun inhalasi. Tujuan: Untuk mengetahui manfaat aromaterapi lavender sebagai penurun tingkat kecemasan persalinan. Metode: Metode yang digunakan oleh penulis adalah studi literatur dari berbagai jurnal nasional maupun internasional. Metode ini digunakan dengan tujuan menyajikan, menambah pengetahuan dan pemahaman mengenai topik yang dibahas dengan meringkas materi yang telah diterbitkan serta memberikan informasi fakta atau analisis baru dari tinjauan literatur yang relevan kemudian membandingkan hasil tersebut dalam artikel. Hasil: lavender yang mengandung camphor, terpinen-4-ol, linalool, linalyl acetate, beta-ocimene dan 1, 8-cineole terbukti efektif sebagai Complementary and Alternative Medicine analgesi yang dapat menurunkan tingkat kecemasan persalinan, baik diaplikasikan secara inhalasi maupun pemijatan. Kesimpulan: Aromaterapi lavender dapat digunakan sebagai penurun tingkat kecemasan persalinan.

\section{Abstract}

Background: Anxiety is mental condition filled with worry about what might happen. Anxiety will increase when the mother feels the pain of giving birth to her baby. Strategy to reduce anxiety level can use lavender aromatherapy by doing massage or inhalation. Purpose: To determine the benefits of lavender aromatherapy as a reduction in labor anxiety levels. Method: The method used by the author is literature study from various national and international journals. This method is used with the aim of presenting,
\end{abstract}


increasing knowledge and understanding of the topics discussed by summarizing the material that has been published and providing factual information or new analysis from relevant literature reviews and then comparing the results in the article. Results: lavender containing camphor, terpinen-4-ol, linalool, linalyl acetate, beta-ocimene and 1, 8 -cineole was proven effective as a Complementary and Alternative Medicine analgesic that can reduce the level of labor anxiety, either applied by inhalation or massage. Conclusion: Lavender aromatherapy can be used to reduce the level of anxiety of labor.

\author{
Keywords: \\ Aromatherapy; \\ Lavender; \\ Kecemasan Persalinan;
}

Coresponden author:

Email: annisaridhas@gmail.com

artikel dengan akses terbuka dibawah lisensi CC BY 4.0

\section{Pendahuluan}

Persalinan merupakan suatu proses janin, plasenta, dan membran keluar melalui jalan lahir dari rahim. Proses persalinan diawali dengan adanya pembukaan dan dilatasi serviks yang terjadi akibat adanya frekuensi, durasi, dan kekuatan yang teratur pada kontraksi uterus. Kekuatan kontraksi uterus yang muncul diawali dengan kekuatan yang kecil, dan terus meningkat mencapai puncaknya yaitu pembukaan serviks yang sudah lengkap. Pembukaan serviks yang lengkap merupakan pembukaan yang siap untuk rahim ibu mengeluarkan janin (Rohani et al,2011). Berdasarkan DSM-V, gangguan kecemasan terdiri dari gangguan mental non-psikotik, gangguan kecemasan umum, fobia, serangan panik, gangguan obsesif kompulsif, dan gangguan lain yang termasuk dalam kategori yang lebih luas "gangguan kecemasan tanpa spesifikasi lain" (American Psychiatric Association, 2013). Secara umum, gangguan kecemasan memiliki ciri-ciri ketakutan dan kecemasan yang berlebihan, serta gangguan perilaku terkait. Sementara ketakutan adalah respons emosional terhadap ancaman yang akan segera terjadi, yang ditandai dengan aktivasi sistem otonom akut, kecemasan juga digambarkan sebagai "antisipasi ancaman masa depan" (Donelli et al., 2019).

Ibu hamil dengan usia kurang dari 20 tahun atau lebih dari 35 tahun merupakan usia hamil resiko tinggi karena dapat terjadi kelainan atau gangguan pada janin, sehingga dapat menimbulkan kecemasan pada ibu hamil tersebut (Handayani, 2015). Kecemasan ibu hamil yang tinggi bisa mengakibatkan dampak yang buruk pada ibu dan janinnya. Kejadian BBLR (Berat Badan Lahir Rendah), kelahiran preterm, kromosomial abortus spontan salah satunya disebabkan oleh kecemasan ibu selama kehamilan. Selain itu kecemasan juga mengakibatkan hambatan pada persalinan dan komplikasi kehamilan (Sianipar et al., 2017). Banyak metode telah digunakan untuk manajemen nyeri selama persalinan, baik secara farmakologis maupun non-farmakologis teknik. Metode yang umum digunakan adalah dengan menggunakan obat penghilang rasa sakit secara intravena, seperti meperidine, morfin atau fentanil. Namun hal itu mungkin dapat menyebabkan hasil buruk pada neonatus, terutama supresi pernapasan. Apalagi para ibu dapat memiliki risiko aspirasi, ventilasi yang tidak memadai, pusing, mual dan dosis yang berlebihan (Jones et al., 2012). Complementary and Alternative Medicine (CAM) sebagai analgesia persalinan sedang popular dalam dekade terakhir. Aromaterapi adalah salah satu jenis dari CAM yang banyak digunakan dengan tujuan menghirup uap atau penyerapan minyak ke dalam kulit yang berguna mengobati atau mengurangi gejala fisik 
dan emosional (Dhany, 2017). Olahraga berpotensi membantu mengatasi hambatan untuk meningkatkan tingkat aktivitas fisik diantara wanita hamil (Ayuningtyas, 2019).

Aromaterapi menggunakan minyak lavender dipercaya dapat memberikan efek relaksasi bagi saraf dan otot-otot yang tegang (carminative) setelah lelah beraktivitas. Lavender mempunyai efek relaksasi sekaligus perangsang sehingga sangat baik digunakan sebagai penyejuk bagi orang-orang yang cemas dan perangsang bagi orang yang mengalami depresi. Aromaterapi lavender juga dapat mengatasi masalah sakit sendi, sakit kepala atau nyeri lainnya (Suprijati, 2014).

\section{Metode}

Metode yang digunakan oleh penulis adalah studi literatur dari berbagai jurnal nasional maupun internasional. Studi literatur dilakukan dengan cara membaca, memahami, dan mereview literatur dari berbagai macam sumber Metode ini digunakan dengan tujuan menyajikan, menambah pengetahuan dan pemahaman terkini mengenai topik yang dibahas dengan meringkas materi yang telah diterbitkan serta memberikan informasi fakta atau analisis baru dari tinjauan literatur yang relevan kemudian membandingkan hasil tersebut dalam artikel.

\section{Hasil Dan Pembahasan}

Persalinan adalah proses dimana bayi, plasenta dan selaput ketuban keluar dari rahim ibu. Persalinan dianggap normal jika proses terjadinya pada usia kehamilan cukup bulan (setelah $37 \mathrm{minggu}$ ) tanpa disertai dengan penyulit (Sulistyawati, 2013). Di Indonesia terdapat 373.000 .000 orang ibu hamil, yang mengalami kecemasan dalam menghadapi persalinan ada sebanyak 107.000 .000 orang $(28,7 \%)$. Di Indonesia penelitian yang dilakukan pada primigravida trimester III sebanyak 33,93\% mengalami kecemasan. Penelitian lain menyebutkan bahwa ibu hamil normal dalam menghadapi persalinan mengalami 47,7\% kecemasan berat, 16,9\% kecemasan sedang, dan 35,4\% mengalami kecemasan ringan (Roniarti et al., 2017). Kecemasan adalah suatu kondisi kejiwaan yang penuh dengan kekhawatiran terhadap apa yang mungkin terjadi. Menghadapi proses persalinan merupakan salah satu faktor yang dapat menimbulkan kecemasan, dimana mengingat proses melahirkan bayi tidak selalu somatic sifatnya akan tetapi bersifat psikosomatic, sebab banyak elemen psikis ikut mempengaruhi kelancaran atau kelambatan proses melahirkan bayi tersebut. Kecemasan akan meningkat pada saat ibu merasakan tanda-tanda kesakitan melahirkan bayinya (Yuliani \& Widyawati, 2018).

Tingkat kecemasan dapat diukur dengan instrumen skala kecemasan yang dibuat oleh Hamilton, yang disebut sebagai HARS (Hamilton Anxiety Rating Scale). Skala kecemasan tersebut terdiri dari 14 petanyaan dengan jumlah skoring item antar 0 (tidak ada kecemasan) hingga 4 (kecemasan tinggi) dengan total skor yang memiliki interval antara 0 sampai 56. Dengan kriteria skala kecemasan sebagai berikut; Tidak cemas bila skor kurang dari 14; cemas ringan bila skor 15-20; cemas sedang bila skor 21-27; cemas berat bila skor 28 - 41; cemas berat sekali bila skor 42-56 (Suprijati, 2014). Upaya yang dapat dilakukan untuk menurunkan tingkat kecemasan pada persalinan adalah dengan pemberian aromaterapi. Aromaterapi adalah ilmu yang memanfaatkan essentials oil konsentrasi tinggi atau esens yang disuling dari tumbuhan untuk mempertahankan sifat terapeutiknya. Minyak tersebut dapat diaplikasikan melalui pemijatan di kulit, atau dihirup. Penerapan aromaterapi yang paling umum selama persalinan adalah dengan pijat, mandi atau menghirup melalui infus uap (Kaviani, 2014). Hutasoit (2002) 
mengungkapkan cara kerja aromaterapi yaitu ketika hidung menghirup wangi minyak essensial yang telah terbukti mampu mempengaruhi emosi. Minyak yang dihirup akan membuat vibrasi di hidung. Dari sini minyak yang mempunyai manfaat tertentu itu akan mempengaruhi sistem limbik, tempat pusat memori, suasana hati, dan intelektualitas berada. (Mustar, 2020) berpendapat bahwa terdapat hubungan antara pengetahuan dan pendidikan ibu hamil dan ibu bersalin dengan tradisi dalam menghadapi kehamilan dan persalinan.

Manfaat aromaterapi selain meningkatkan keadaan fisik dan psikologis, aromaterapi dapat memberikan efek relaksasi bagi saraf dan otot-otot yang tegang. Relaksasi merupakan salah satu cara untuk mengatasi kecemasan atau stress melalui pengendoran otot-otot dan syaraf. Relaksasi dapat meningkatkan kesehatan secara umum dengan memperlancar proses metabolisme tubuh, menurunkan tingkat agresifitas dan perilakuperilaku buruk dari dampak stress, meningkatkan rasa harga diri dan keyakinan diri, pola pikir menjadi lebih matang, mempermudah dalam mengendalikan diri, mengurangi stress secara keseluruhan, dan meningkatkan kesejahteraan. Respon relaksasi ini yang membuat ibu persalinan kala I mengalami penurunan skor tingkat kecemasan sehingga memperlancar proses persalinan. Oleh karena itu salah satu cara relaksasi yang digunakan untuk menurunkan kecemasan ialah dengan pemberian aromaterapi (Octhaviany, 2015).

Lavender (Lavandula officinalis) yang merupakan keluarga Lamiaceae, merupakan tanaman yang sering digunakan dalam aromaterpi. Lavender mengandung camphor, terpinen-4-ol, linalool, linalyl acetate, beta-ocimene dan 1, 8-cineole. Studi terhadap manfaat aromaterapi lavender, telah menunjukan bahwa linalool dan linalyl acetate yang terdapat pada lavender dapat menstimulasi sistem parasimpatik. Sebagai tambahan, linalyl acetate memiliki efek narkotik dan linalool berperan sebagai sedative (Ali et al., 2015).

Efek essentials oil lavender pada kecemasan selama tahap pertama persalinan telah diteliti dalam berbagai penelitian. Aromaterapi lavender melalui inhalasi digunakan dalam studi yang dilakukan oleh Mirzai et al., (2009). Dalam studi tersebut, 121 ibu bersalin dibagi ke dalam dua kelompok. Kelompok pertama diberikan inhalasi essentials oil lavender sebanyak $0,2 \mathrm{ml}$ dan air distilasi sebanyak $2 \mathrm{ml}$ selama 60 menit. Sementara kelompok kedua hanya diberikan air distilasi sebanyak 2 ml. dilaporkan bahwa tingkat kecemasan pada kelompok inhalasi lavender secara signifikan lebih rendah dibandingkan dengan kelompok kontrol 60 menit setelah intervensi, dengan nilai $\mathrm{p}(\mathrm{P}<0,001)$. Studi tersebut sejalan dengan penelitian yang dilakukan oleh Suprijati (2014), terhadap $100 \mathrm{ibu}$ bersalin. Hasil penelitian menunjukkan ada pengaruh yang signifikan antara pemberian aromaterapi dalam menurunkan kecemasan menghadapi persalinan. Nilai rata-rata kecemasan menghadapi persalinan sebelum diberi perlakukan aromaterapi (pre test) = 26,41 . Nilai rata-rata menghadapi persalinan setelah diberi perlakuan aromaterapi (post test) $=23,41$. Nilai rata-rata ini dapat diinterprestasi bahwa ada penurunan atau selisih rata-rata kecemasan ibu hamil trimester III menghadapi persalinan sebelum dan sesudah diberi perlakuan (aromaterapi).

Penggunaan aromaterapi lavender dengan cara pemijatan (massage) juga dilakukan pada beberapa penelitian, seperti penelitian yang dilakukan Lamadah dan Nomani (2016) terhadap 60 ibu bersalin. Penelitian tersebut membandingkan 2 kelompok, dimana kelompok pertama diberikan pemijatan punggung dengan tambahan 2 tetes essentials oil lavender yang diencerkan dalam 50 cc minyak almond. Sedangkan, kelompok kedua hanya diberikan pemijatan punggung saja. Dilaporkan bahwa tingkat kecemasan pada kelompok pertama secara signifikan mengalami penurunan. Hal ini karena saat pemijatan dengan aromaterapi lavender diterapkan di atas kulit dan masuk ke dalam aliran darah melalui 
pori-pori kulit, hal ini menyebabkan rasa nyaman dan mengurangi kebutuhan akan metode pereda nyeri yang bersifat invasif (Janula, 2014). Pemijatan juga dapat meningkatkan endorfin, merangsang saraf yang menurunkn nyeri, meningkatkan sirkulasi dan meningkatkan aliran darah dan oksigenasi jaringan (Jones, 2013). Sampai saat ini belum ada penelitian yang mengungkapkan bahwa aromaterapi lavender dapat membahayakan ibu dan janinnya (Tracey, 2015). Berdasarkan penelitian tersebut, bahwa aromaterapi lavender terbukti efektif sebagai Complementary and Alternative Medicine (CAM) analgesi yang dapat menurunkan tingkat kecemasan persalinan, baik diaplikasikan secara inhalasi maupun pemijatan.

\section{Simpulan Dan Saran}

Aromaterapi lavender dapat digunakan sebagai penurun tingkat kecemasan persalinan. Dengan kandungan camphor, terpinen-4-ol, linalool, linalyl acetate, beta-ocimene dan 1, 8cineole pada lavender, dapat menstimulasi sistem parasimpatik dan dapat menimbulkan efek relaksasi. Masih perlu dilakukan penelitian lebih lanjut, untuk mengetahui dosis efektif dari penggunaan aromaterapi sebagai penurun tingkat kecemasan persalinan.

\section{Daftar Rujukan}

Ali, B., Al-Wabel, N, A., Shams, S., Ahamad, A., Khan, S, A., Anwar, F. 2015. Essential Oils Used in Aromatherapy: A Systemic Review. Asian Pac J Trop Biomed. 5 (8): 601-11. doi:10.1016/j. ap jtb.2015.05.007.

American Psychiatric Association. 2013. Diagnostic and Statistical Manual of Mental Disorders (DSM-5), Fifth Edition. Washington DC: American Psychiatric Association Pub.

Ayuningtyas, N. (2019). Olahraga dan Depresi pada Wanita Hamil. Jurnal Ilmiah Kesehatan Sandi Husada, 10 (2 SE-Articles). Retrieved from https://akper-sandikarsa.ejournal.id/JIKSH/article/view/124

Dhany, A,L., Mitchell, T., Foy, C. 2012. Aromatherapy and massage intrapartum service impact on use of analgesia and anesthesia in women in labor: a retrospective case note analysis. J Altern Complement Med. 18:932-938

Donelli, D., Antonelli, M., Bellinazzi, C., Gensini, G,F., Firenzuoli, F. 2019. Effects of Lavender on Anxiety: A Systematic Review and Meta-analysis. Elshevier Journal Phytomedicine. 65(1): 1-31.

Handayani, R. 2015. Faktor-Faktor yang Berhubungan dengan Tingkat Kecemasan Menjelang Persalinan pada Ibu Primigravida Trimester III. Ners Jurnal Keperawatan Vol.10(46): 2-71.

Hutasoit, Aini S. 2002. Panduan Aromatherapy Untuk Pemula. Jakarta: Gramedia Pustaka Utama.

Kaviani, M., Maghbool, S., Azima, S., Hosein, M. 2014. Comparison of The Effect of Aromatherapy with Jasminum Officinale and Salvia Officinale on Pain Severity and Labor Outcome in Nulliparous Women. Iran J Nurs Midwifery Res. 19(6): 666-672.

Janula, R., Mahipal, S. 2014. Effectiveness of Aromatherapy and Biofeedback in Promotion of Labour Outcome during Childbirth among Primigravidas. International Journal of Health Sciences \& Research. 4(2): 124-128.

Jones, L., Othman, M., Dowswell, T., Alfrevic, Z., Gates, S., Newburn, M., Jordan, S., Lavender, T., Neilson, JP. 2012. Pain Management For Women In Labour: An Overview Of Systematic Reviews. Cochrane Database Syst Rev.

https://doi.org/10.1002/14651858.CD009234. pub2 
Lamadah, S, M., Nomani, I. 2016. The Effect of Aromatherapy Massage Using Lavender Oil on The Level of Pain and Anxiety During Labour among Primigravida Women. Am J Nurs Sci. 5 (2): 37-44. doi: 10.11648 /j.ajns. 20160502.11.

Mustar, M. (2020). Faktor yang Berhubungan dengan Tradisi Masyrakat dalam Menghadapi Kehamilan dan Persalinan Di Desa Welado. Jurnal Ilmiah Kesehatan Sandi Husada, 11(1 SE-Articles). https://doi.org/10.35816/jiskh.v11i1.342

Mirzai, F., Keshtgar, S., Kaviani, M., Rejaefard, A, H. The Effect of Lavender Essence Smelling During Labor on Cortisol and Serotonin Plasma Levels and Anxiety Reduction in Nulliparous Women. Journal of Kerman University of Medical Sciences 2009. 16 (3): 245-54.

Octhaviany, Riana. 2015. Pengaruh Aromaterapi Terhadap Penurunan Kelelahan Kerja di Rumah. Naskah Publikasi Skripsi. Psikologi Universitas Sumatera Utara

Rohani., Saswita, R., Marisah. 2011. Asuhan Kebidanan pada Masa Persalinan. Jakarta: Salemba Medika.

Roniarti, M, P., Mulyani, N., Diana, H. 2017. Pengaruh Endorphine Massage terhadap Tingkat Kecemasan Ibu Primigravida Usia Kehamilan $>36$ Minggu dalam Menghadapi Persalinan. Jurnal Kesehatan Bakti Tunas Husada. 17(2): 212-221.

Sianipar, K., Sinaga R., Nainggolan, Y. 2017. Pengaruh Aromatherapi, Relaksasi Oto Progresif terhadap Penurunan Kecemasan Ibu Hamil Menjelang Persalinan di Bpm Simalungun. Jurnal Ilmiah PANNMED. 12(1): 81-91.

Sulistyawati, A. 2013. Kebidanan. Jakarta: Salemba Medika.

Suprijati. 2014. Efektivitas Pemberian Aromaterapi untuk Menurunkan Kecemasan Ibu Hamil Trimester III dalam Persiapan Menghadapi Persalinan di Bidan Praktek Mandiri Suprijati Desa bagi Kecamatan/ Kabupaten Madiun. Jurnal Delima Harapan. 2(1):58-65.

Tracey. 2011. What is aromatherapy. Health Resources. 14(2):23-25.

Yuliani, D, R., Widyawati, M, N. 2018. Terapi Murottal Sebagai Upaya Menurunkan Kecemasan dan Tekanan Darah pada Ibu Hamil dengan Preeklampsia . Jurnal Kebidanan. 18(2): 79-98. 